\title{
Simulation of boost AC-AC converter using single-phase matrix converter
}

\author{
Zeynep Bala Duranay, Hanifi Guldemir \\ Department of Electrical-Electronics Engineering, Technology Faculty, Firat University, Elazig, Turkey
}

\begin{tabular}{l} 
Article Info \\
\hline Article history: \\
Received Apr 4, 2021 \\
Revised Jun 24, 2021 \\
Accepted Jul 23, 2021 \\
\hline
\end{tabular}

\section{Keywords:}

AC-AC converter

Boost converter

Matrix converter

Pulse width modulation

Total harmonic distortion

\begin{abstract}
Generally, AC-AC converters are implemented using thyristors. These converters generate harmonics and have a low power factor. To eliminate these problems matrix converters (MC) are become used as AC-AC converter. Matrix converters have the capability of being used as frequency changer, rectifier, inverter and chopper. In this work, it is proposed to achieve the desired output of AC-AC Boost converter using single phase matrix converter (SPMC). The operation of single-phase AC-AC boost converter using MC is studied in this paper. The output voltage of this boost converter is higher than the AC input supply voltage. insulated gate bipolar transistors (IGBTs) are used as the switching elements in the SPMC power circuit. Sinusoidal Pulse width modulation (SPWM) technique is applied to generate switching signals to obtain the output voltage. The model of the matrix converter is constructed in MATLAB/Simulink programming software package. The behavior of SPMC is simulated with various switching frequencies. The simulation results together with harmonic spectrum and total harmonic distortion (THD) values are presented. Successful operation of boost SPMC is achieved.
\end{abstract}

This is an open access article under the CC BY-SA license.

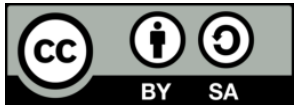

\section{Corresponding Author:}

Zeynep Bala Duranay

Department of Electrical-Electronics Engineering

Firat University

Elazig 23119, Turkey

Email: zbduranay@ firat.edu.tr

\section{INTRODUCTION}

Some industrial applications require an AC-AC conversion. AC voltage controllers with thyristors were performed this AC-AC conversion. This type of circuits distorts voltage and current waveform and have a low power factor. Therefore, power factor correction and harmonic reduction are necessary for these voltage regulators. To overcome these problems matrix converters has taken place of the AC voltage controllers. In a matrix converter (MC) circuit there are input and output lines. Matrix converter consists of bidirectional switches arranged in matrix form, connected between input and output lines. The output lines are connected to input lines in accordance with a strategy [1]. This converter topology has the advantage of no dc link storage element [2]. Up to now, many types of research are done on single phase matrix converter (SPMC) in the field of AC-AC [3]-[5], DC-DC [6], [7], DC-AC [8], [9] and AC-DC [10], [11] conversion.

MC topology is first proposed in [12] and the SPMC circuit was first implemented in [13]. This SPMC implementation has a matrix of input and output lines with switching elements which connect the input to the output. The switches in the converter circuit are both capable of conducting current in both directions that is bidirectional and capable of blocking voltage. Many research works have been done on SPMC implementation [4]-[9], [14]-[16]. 
Matrix converters can produce an output with variable voltages and frequencies. Various circuit topologies such as frequency changer, rectifier, inverter and chopper can be constructed with the MC with simple structure and high reliability. Because the boost $\mathrm{MC}$ is poorly studied in the literature, it is aimed to emphasize the boost characteristics of the matrix converter. Therefore, in this study, a single-phase boost AC$\mathrm{AC}$ matrix converter is studied which has a higher output voltage than a low input voltage. Insulated gate bipolar transistors (IGBTs) are used as switching elements in the SPMC circuit. The output voltage is obtained through duty cycle control of switching device using the sinusoidal pulse width modulation (SPWM) technique. A resistive load is used with an LC filter for removing ripples at the load. An inductance is connected in series with the input supply for boost operation. A model of SPMC for boost AC-AC operation is developed in Simulink. The validation of the model is performed through simulations. The model is tested with different switching frequencies. The simulation results show the successful boost operation of SPMC.

\section{SINGLE PHASE BOOST AC-AC MATRIX CONVERTER}

One of the practical problems faced in the implementation of MC is commutation. Due to having no freewheel paths, the safe transfer of the current between the switches is difficult. The switching has to be so done as to maintain continuous load current and prevent short circuit. The commutation of current can generate over voltages that can disturb the semiconductor switches. For inductive loads, at the switch turn off instants there need to be an alternative current flow path that avoids over voltages. For this, four bidirectional switches in which current flow in both directions are used in the SPMC circuit as in Figure 1. An antiparallel IGBT and diode pairs, as represented in Figure 2, is connected to obtain the bidirectional switches. Diodes are used to add reverse blocking capability to bidirectional switches.

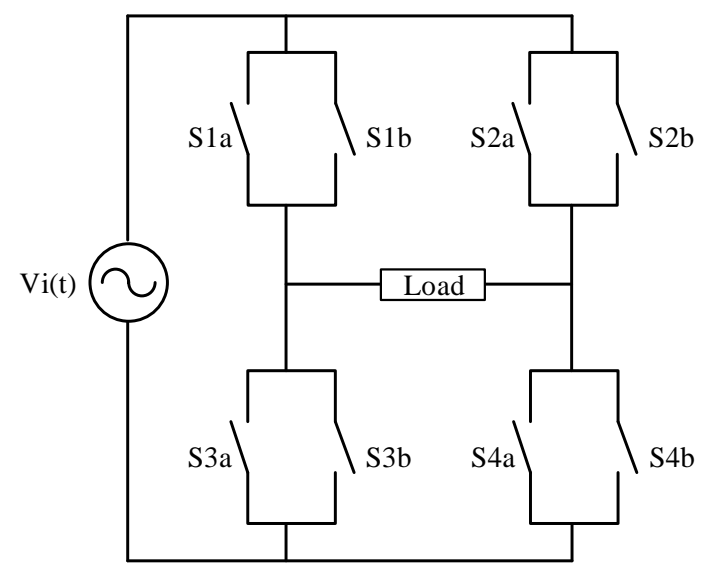

Figure 1. Single phase matrix converter

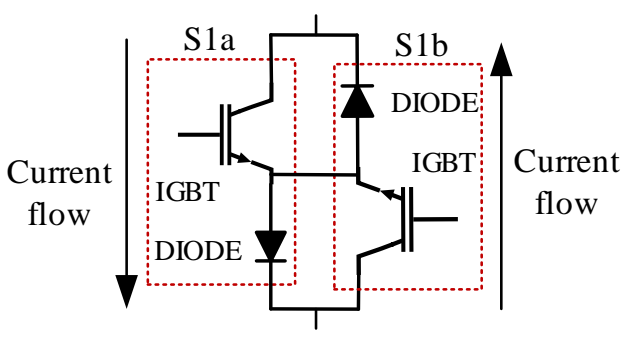

Figure 2. A bidirectional switch

The studied converter circuit topology is given in Figure 3. A load is connected to the output of the converter. This load comprises a resistive load and an LC filter. An inductor L is connected in series with the supply to provide boost operation. 


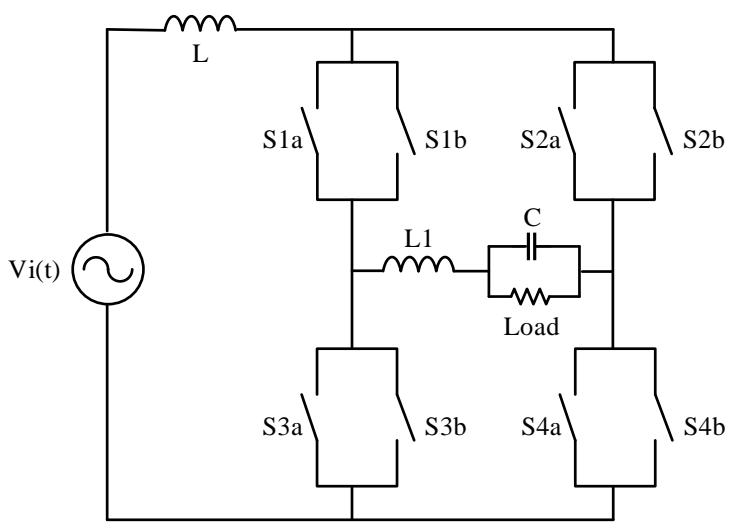

Figure 3. SPMC circuit

\section{SINUSOIDAL PWM}

Due to its simplicity, SPWM is one of the most common used methods in power electronic circuits for digitally control of the switching commutation [17]. This modulation technique has advantages of reduced filtering requirements, less mathematical calculations, and high transmitted of effective power. In SPWM method, which is presented in Figure 4, basically, a high frequency sawtooth shaped carrier signal, $\mathrm{Vc}$, is compared with a sinusoidal reference signal, $\mathrm{Vr}$, with the desired frequency. The switching times are determined by the intersect points of the reference and carrier waves [6]-[13].
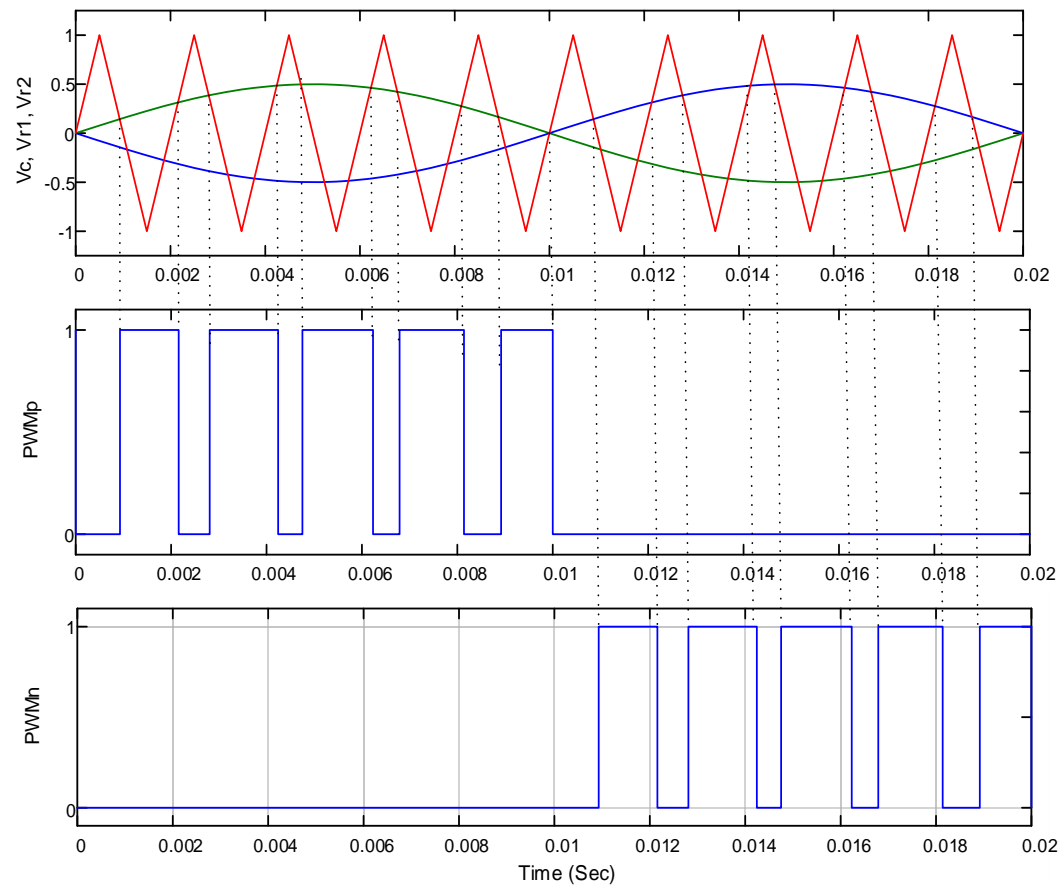

Figure 4. PWM signal production

The modulation scheme uses the SPWM technique to obtain a signal which resembles of the reference sinusoidal signal. That is, the produced signal implicitly includes the amplitude and frequency information of the modulating wave. SPWM scheme block diagram is given in Figure 5.

The ratio of magnitude of the reference wave $(\mathrm{Vr})$ to the magnitude of the carrier wave $(\mathrm{Vc})$ is defined as the modulation index (Mi). Generally, the carrier signal Vc has a fixed amplitude. The output voltage can be changed by controlling the Mi [18]. 


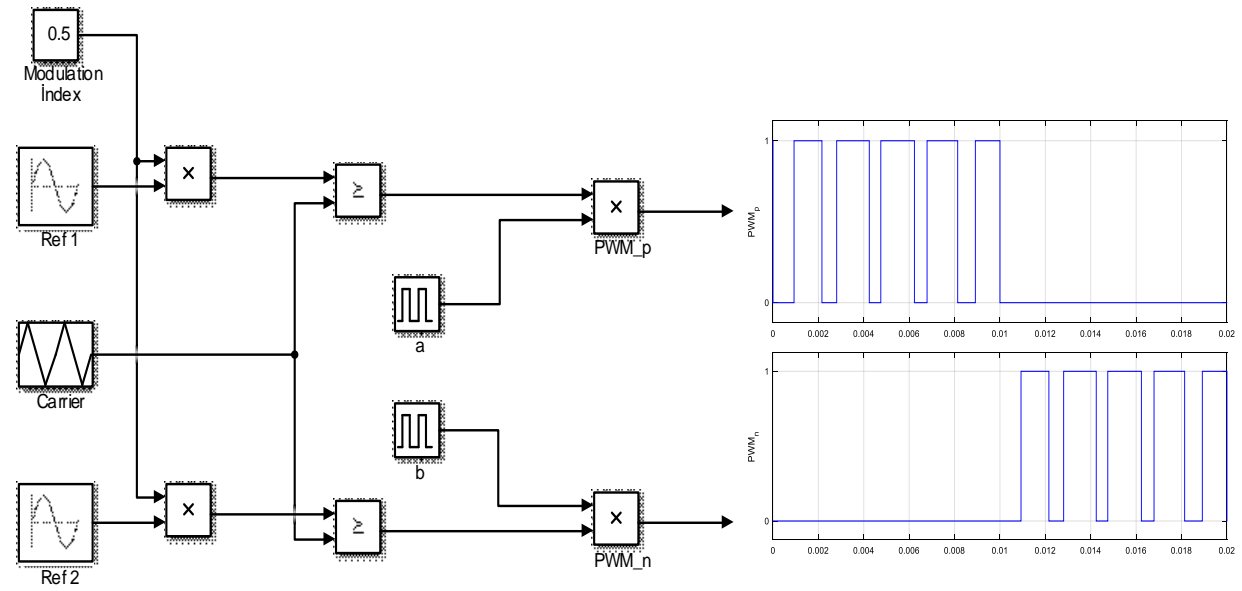

Figure 5. PWM signal production block

\section{SPMC MODES}

SPMC has different topologies and operation modes depending on commutation scheme. These modes of SPMC are chopper, buck, boost, rectifier, rectifier with power factor correction and cycloconverter.

One of the operation mode of the matrix converters is AC-AC converter or cycloconverter. In this mode, the matrix converter is used to obtain AC voltage with variable amplitude and frequency without DC link. The control system is used to produce SPWM patterns to control the power switches.

\subsection{Boost AC-AC operation}

The boost AC-AC converter has four operation modes as shown in Figure 6. Two of the operation modes occur in the first half period and the other two operation modes occur in the next half period. The current flow for commutation switches is represented by bold line and the control (SPWM) switch is represented by the dotted line.

Mode 1 is the charging operation mode and starts when both switches S1a and S3a are closed. The input current through the inductor rises.

Mode 2 is the discharging operation mode. This mode starts when switches S1a and S4a are closed while S3a is open. The current flowing through S3a in mode 1 is transferred to the load in mode 2. The inductor current decreases till S3a has turned on again. The load receives the stored energy of the inductor L.

The other two modes have the same operation during the next half period.

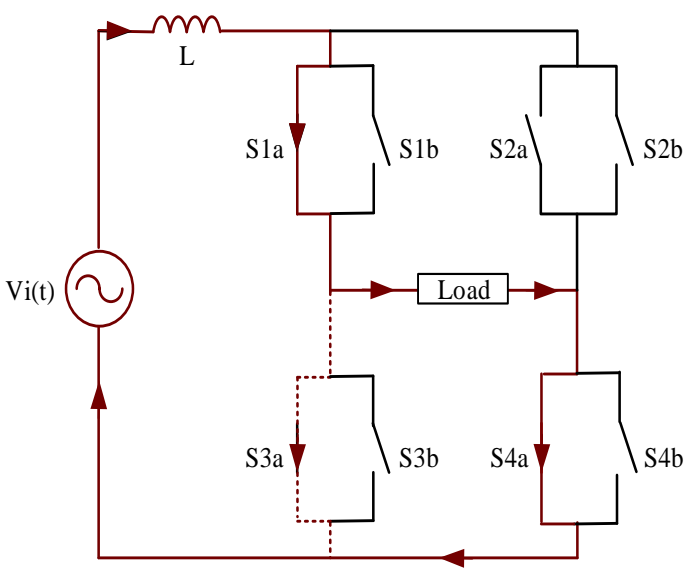

(a)

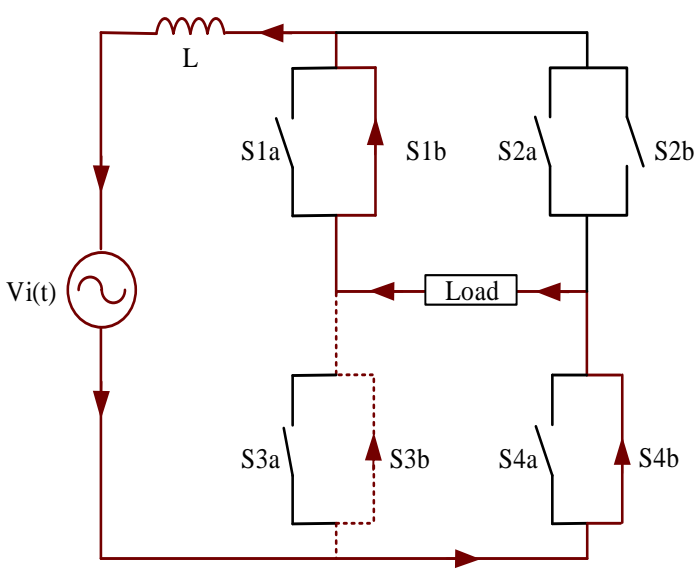

(b)

Figure 6. Boost AC-AC converter topology: (a) Positive cycle, (b) Negative cycle 


\section{MODELING AND SIMULATION RESULTS}

The boost SPMC is modeled using MATLAB/Simulink. The converter circuit parameters are listed in Table 1. The Simulink model of boost AC-AC converter with SPMC and switching signal production are shown in Figure 7 and Figure 8 respectively. The comparison of the sinusoidal reference wave with the triangular carrier wave produces the PWM signals. The triangular carrier wave is produced with the "Repeating Sequence" block of the Simulink.

Table 1. Parameters of SPMC

\begin{tabular}{lc}
\hline \multicolumn{1}{c}{ Component } & Value \\
\hline Supply Voltage & $15 \mathrm{Vp}$ \\
Boost Inductor & $20 \mathrm{mH}$ \\
Load Resistor & $50 \Omega$ \\
LC Filter & $5 \mathrm{mH}, 570 \mu \mathrm{F}$ \\
\hline
\end{tabular}

The switching scheme for SPMC as a boost AC-AC converter, as explained in section iv, is listed in Table 2 and the switching algorithm is given by Figure 9 for $50 \mathrm{~Hz}$ operation.
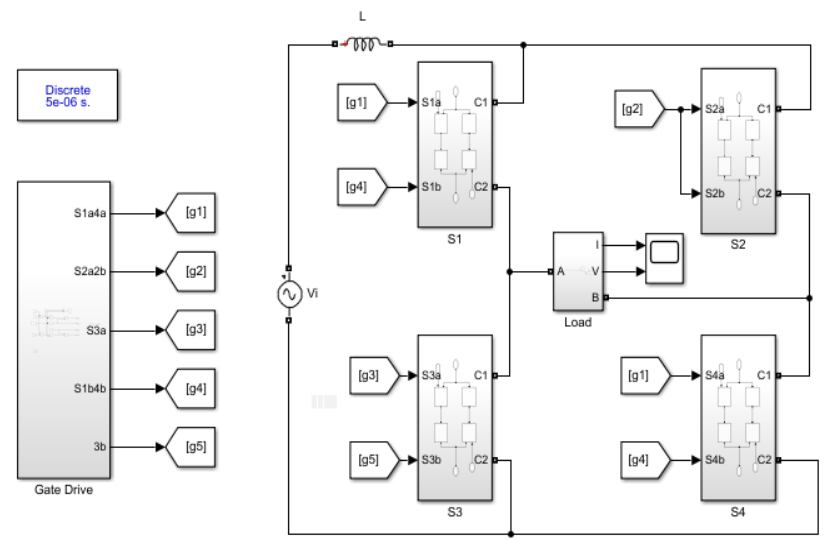

Figure 7. Single phase boost matrix converter

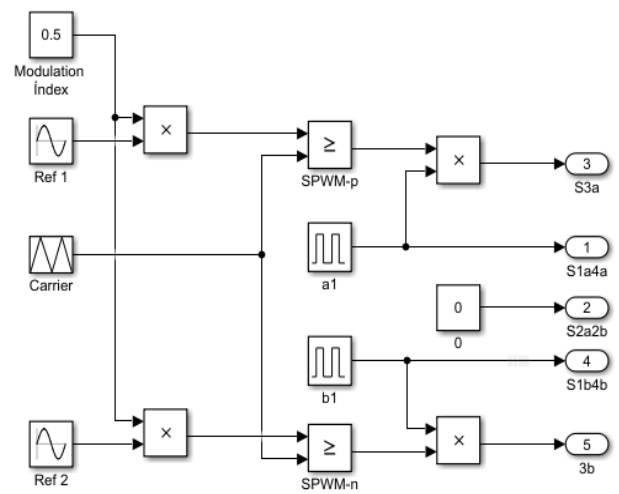

Figure 8. PWM signal generation for switch gates

Table 2. Switching strategy

\begin{tabular}{|c|c|c|c|c|c|c|c|c|c|}
\hline \multicolumn{2}{|c|}{ Switches } & S1a & S1b & $\mathrm{S} 2 \mathrm{a}$ & $\mathrm{S} 2 \mathrm{~b}$ & S3a & S3b & $\mathrm{S} 4 \mathrm{a}$ & $\mathrm{S} 4 \mathrm{~b}$ \\
\hline \multirow[t]{2}{*}{ Positive Cycle } & Mode1 & $\mathrm{ON}$ & OFF & OFF & OFF & ON & OFF & ON & OFF \\
\hline & Mode2 & $\mathrm{ON}$ & OFF & $\mathrm{OFF}$ & OFF & $\mathrm{OFF}$ & OFF & $\mathrm{ON}$ & OFF \\
\hline \multirow[t]{2}{*}{ Negative Cycle } & Mode3 & OFF & ON & OFF & OFF & OFF & $\mathrm{ON}$ & OFF & $\mathrm{ON}$ \\
\hline & Mode4 & OFF & ON & OFF & OFF & OFF & OFF & OFF & $\mathrm{ON}$ \\
\hline
\end{tabular}



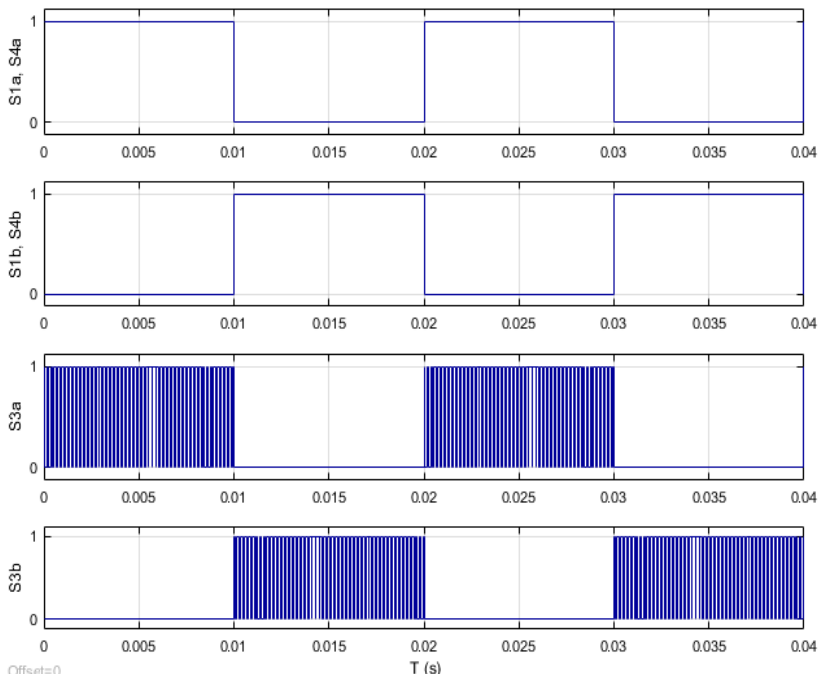

Figure 9. Switching algorithm of AC-AC boost SPMC

The boost SPMC model is simulated with the parameters listed in Table 1. Figure 10 and Figure 11 present the obtained output voltages with switching frequency of $5 \mathrm{KHz}$ and $10 \mathrm{KHz}$ respectively. The modulation index, mi, for each simulation, is set to $0.5 .15 \mathrm{~V}$ peak input voltage is used in the simulations. The produced output voltage is $46.33 \mathrm{~V}$ peak for switching frequency of $5 \mathrm{KHz}$ and $51.1 \mathrm{~V}$ peak for switching frequency of $10 \mathrm{KHz}$.

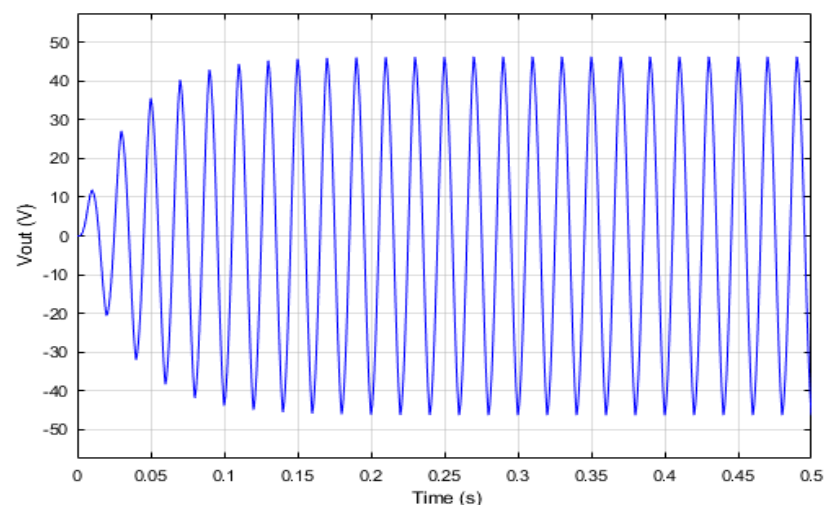

Figure 10. SPMC output voltage with switching frequency $\mathrm{fc}=5 \mathrm{KHz}$

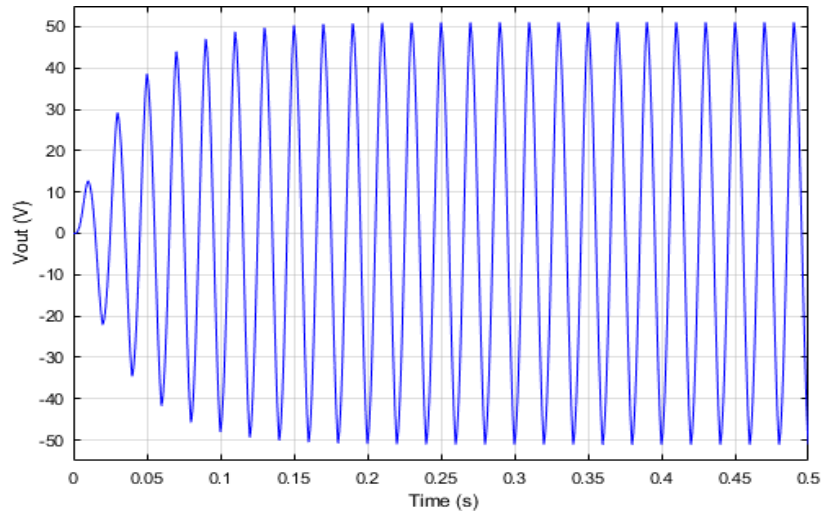

Figure 11. SPMC output voltage with switching frequency fc $=10 \mathrm{KHz}$ 
Figure 12(a) and 12(b) represent the spectrum analysis for measuring THD of output voltage for switching frequencies $5 \mathrm{KHz}$ and $10 \mathrm{KHz}$ respectively. It can be seen in the simulations presented, increasing the carrier wave frequency, increases the output voltage. The simulations show that the output voltage is about 3 times higher than that of the input. The total harmonic distortions (THD) are $3.56 \%$ and $3.71 \%$ for $5 \mathrm{Khz}$ and $10 \mathrm{Khz}$ switching frequencies respectively. The total harmonic distortion calculated for the simulations presented stays within the standards. The IEEE standard for THD is $5 \%$ [19], [20].

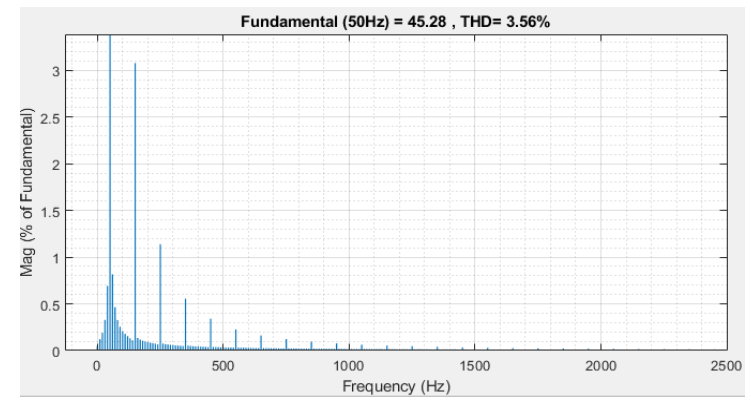

(a)

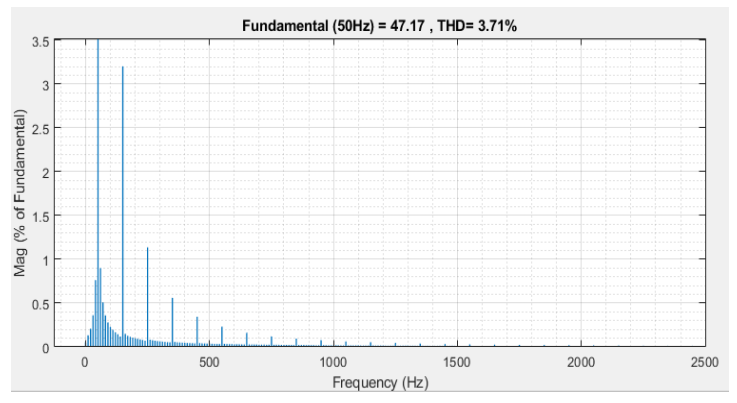

(b)

Figure 12. Harmonic spectrum of output voltage: (a) fc=5 KHz, (b) fc=10 KHz

\section{CONCLUSION}

A study of boost AC-AC converter using SPMC is studied in this paper. The system is implemented in MATLAB/Simulink environment. The converter circuit is constructed using IGBT and diode pairs which are so connected to allow bidirectional current flow. The system is simulated with different switching frequencies. The simulation results have shown that the boost AC-AC converter with SPMC produce higher $\mathrm{AC}$ output voltage from a given AC supply voltage. It has been observed from the simulation results that changing the modulation index has no effect on the value of output voltage.

\section{REFERENCES}

[1] Z. Idris, M. K. Hamzah and M. F. Saidon, "Implementation of single-phase matrix converter as a direct AC-AC converter with commutation strategies," 2006 37th IEEE Power Electronics Specialists Conference, 2006, pp. 1-7, doi: 10.1109/pesc.2006.1712106.

[2] K. P. Shaik, S. Karimulla and S. M. Irshad, "Simulation of single phase buck boost matrix converter without commutation issues," European Journal of Electrical Engineering, vol. 20, no. 2, pp. 205-214, 2018, doi: 10.3166/EJEE.20.205-214.

[3] A. Khoei and S. Yuvarajan, "Single-phase AC-AC converters using power MOSFETs," in IEEE Transactions on Industrial Electronics, vol. 35, no. 3, pp. 442-443, Aug. 1988, doi: 10.1109/41.3119.

[4] A. K. Gola and V. Agarwal, "Implementation of an efficient algorithm for a single phase matrix converter," Journal of Power Electronics, vol. 9, no. 2, pp. 198-206, 2009.

[5] H. F. Rashag, "Optimization of efficiency for power system using three phase AC to AC matrix converter with the algorithm of fuzzy controller," International Journal of Applied Power Engineering (IJAPE), vol. 8, no. 2, pp. 129133, 2019, doi: 10.11591/ijape.v8.i2.pp129-133.

[6] Z. M. Noor, N. F. A. Rahman and M. K. Hamzah, "Simulation of DC to DC converter using single phase matrix converter topology," 2010 IEEE Symposium on Industrial Electronics and Applications (ISIEA), 2010, pp. 149-154, doi: 10.1109/ISIEA.2010.5679480.

[7] S. Z. Mohammad Noor, M. Kamal Hamzah and A. Farid Abidin, "Modelling and simulation of a DC Chopper using single phase matrix converter topology," 2005 International Conference on Power Electronics and Drives Systems, 2005, pp. 827-832, doi: 10.1109/PEDS.2005.1619799.

[8] M. K. Hamzah, S. Z. M. Noor and S. F. A. Shukor, "A new single-phase inverter using single-phase matrix converter topology," 2006 IEEE International Power and Energy Conference, 2006, pp. 459-464, doi: 10.1109/PECON.2006.346695.

[9] S. Zaliha, M. Noor, M. K. Hamzah, R. Baharom and N. Y. Dahlan, "A new single-phase inverter with bidirectional capabilities using single-phase matrix converter," 2007 IEEE Power Electronics Specialists Conference, 2007, pp. 464-470, doi: 10.1109/PESC.2007.4342032.

[10] R. Baharom, M. K. Hamzah, N. R. Hamzah and L. Mohd Kasim, "Boost rectifier using single-phase matrix converter with bipolar output," 2008 IEEE 2nd International Power and Energy Conference, 2008, pp. 1141-1146, doi: 10.1109/PECON.2008.4762647. 
[11] D. M. Bukari, R. Baharom, A. Idris and M. K. Hamzah, "Boost rectifier using single phase matrix converter with reduced switch counts," 2013 IEEE Business Engineering and Industrial Applications Colloquium (BEIAC), 2013, pp. 593-597, doi: 10.1109/BEIAC.2013.6560198

[12] L. Gyugyi, and B. R. Pelly, Static power frequency changers : Theory, performance, and application, New York: Wiley, 1976

[13] A. Zuckerberger, D. Weinstock, D. Weinstock and A. Alexandrovitz, "Single-phase matrix converter," IEE Proceedings-Electric Power Applications, vol. 144, no. 4, pp. 235-240, 1997, doi: 10.1049/ip-epa:19970848.

[14] H. M. Hanafi, Z. Idris, M. K. Hamzah and A. Saparon, "Modelling \& simulation of single-phase matrix converter as a frequency changer with Sinusoidal pulse width modulation using MATLAB/Simulink," 2006 IEEE International Power and Energy Conference, 2006, pp. 482-487, doi: 10.1109/PECON.2006.346699.

[15] K. B. Tawfiq, A. S. Mansour and E. E. EL-Kholy, "Implementation of ultra-modified symmetric sequence algorithm for space vector modulation of matrix converter," International Journal of Applied Power Engineering (IJAPE), vol. 7, no. 3, pp. 264-276, 2018, doi: 10.11591/ijape.v7.i3.pp264-276.

[16] Z. Idris, M. K. Hamzah and N. R. Hamzah, "Modelling \& simulation of a new single-phase to single-phase cycloconverter based on single-phase matrix converter topology with sinusoidal pulse width modulation using MATLAB/Simulink," 2005 International Conference on Power Electronics and Drives Systems, 2005, pp. 15571562, doi: 10.1109/PEDS.2005.1619936.

[17] P. W. Wheeler, J. Rodriguez, J. C. Clare, L. Empringham and A. Weinstein, "Matrix converters: a technology review," in IEEE Transactions on Industrial Electronics, vol. 49, no. 2, pp. 276-288, April 2002, doi: $10.1109 / 41.993260$.

[18] S. H. Hosseini and E. Babaei, "A new generalized direct matrix converter," ISIE 2001. 2001 IEEE International Symposium on Industrial Electronics Proceedings (Cat. No.01TH8570), 2001, pp. 1071-1076 vol.2, doi: 10.1109/ISIE.2001.931624.

[19] "IEEE recommended practices and requirements for harmonic control in electrical power systems," in IEEE Std 519-1992, pp.1-112, 9 April 1993, doi: 10.1109/IEEESTD.1993.114370.

[20] "IEEE recommended practice for monitoring electric power quality," in IEEE Std 1159-1995, pp.1-80, 30 Nov. 1995, doi: 10.1109/IEEESTD.1995.79050.

\section{BIOGRAPHIES OF AUTHORS}

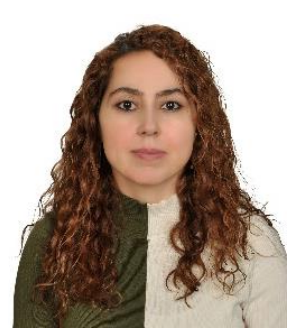

Zeynep Bala Duranay was born in 1985; received the BSc in Electrical and Electronics Engineering from the Faculty of Engineering, University of Firat, Turkey, in 2009; she received MSc from Gazi University, Turkey, in 2013 and PhD in 2017 from the Firat University, Turkey. Now she is assistant professor in Firat University, Technology Faculty. Her research interests are ac drivers, dc-dc converters and renewable energies.

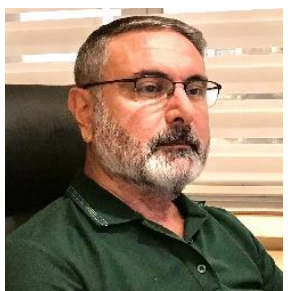

Hanifi Guldemir received the BSc and MSc degrees in Electrical and Electronics Engineering from Firat University, Elazig, Turkey, in 1989 and 1991 respectively, and PhD degree in School of Electrical and Electronics Engineering from Nottingham University, England, in 1999. He is currently a professor in the Department of Electrical and Electronics Engineering at Technology Faculty, Firat University, Elazig, Turkey. His research involves control of electrical drives and power converters. 